\title{
NOVEDADES EPIGRÁFICAS DE EDETA (LLÍRIA, VALENCIA)
}

\author{
EPIGRAPHIC NEWS OF EDETA (LLÍRIA, VALENCIA)
}

\author{
VICENTE ESCRIVÀ TORRES \\ Museo Arqueológico de Llíria
}

CARMEN MARTÍNEZ CAMPS

ANA SABATER PÉREZ

XAVIER VIDAL FERRÚS

Ayuntamiento de Llíria

\section{INTRODUCCIÓN}

La ciudad romana de Edeta (Llíria, Valencia, Hispania citerior, conventus Tarraconensis) está siendo objeto en los últimos años de una intensa actividad arqueológica cuyos resultados destacan la importancia que esta civitas alcanzó entre los ss. I-III d.C., siendo su mayor exponente, hasta la fecha, el conjunto monumental del santuario y termas romanas de Mura (Escrivà, Martínez y Vidal, 2001), construido en época flavia, periodo en el que uno de sus ciudadanos, $M$. Cornelius Nigrinus, ostentó el cargo de consul suffectus en el año 83 d. C. (Alföldy y Halfmann, 1973).

Una primera recopilación sobre las inscripciones romanas de Edeta y su territorio se realizó a finales de los años 90 (Corell 1996), siendo actualizada poco tiempo después (Corell, 2008) y completada con la publicación de un importante conjunto de grafitos sobre cerámica, aparecidos en dos pozos votivos situados en la Avda. dels Furs, n. 24 (Corell et alii, 2012); sin embargo, la actividad arqueológica en la ciudad durante estos cinco últimos años ha proporcionado algunas novedades epigráficas que, aprovechando la ocasión que se nos brinda, daremos a conocer en el presente trabajo.

Las inscripciones inéditas recuperadas son ocho en total, seis realizadas sobre soporte pétreo -dos de las cuales completan pequeños fragmentos publicados con anterioridad- y otras dos sobre dos dolia que formarían parte del instrumentum domesticum.

\section{VOTIVAS}

\section{Ara dedichda a Fortuna}

Dos fragmentos de un ara de piedra caliza rosácea con tonalidades grises tal vez por efecto del fuego, con características propias del Buixcarró. La cara frontal y las dos laterales están pulidas. El basamento es sencillo, rematado con una moldura de cuarto bocel. Uno de los fragmentos, el correspondiente a la parte superior, recuperado en campañas anteriores, fue publicado en el año 1998 (Corell y Escrivà, 1998, 138-139, n. ${ }^{\circ}$ 7; Corell, 2008, 96-97, n. ${ }^{\circ} 48$; vide AE 1998, 794 y HEp 8, 1998, 496).

En el momento actual, se conserva completo el basamento y la práctica totalidad del fuste. Sus dimensiones son $(22,2) \times 22,2 \times 16,5 \mathrm{~cm}$, de las que el basamento tiene $(20,2) \times 15,6 \times 6,6 \mathrm{~cm}$ y el cuerpo $(13) \times$ $15,2 \times 15,2 \mathrm{~cm}$. Presenta muy marcadas las líneas de pautado y la interpunción es triangular hacia arriba. $\mathrm{La}$ altura de las letras es de 2,5 (v. 1) 1,9 (v. 2-3) $1,5 \mathrm{~cm}$. (v. 4-5). Nexo HE en v. 1; en esa línea sólo se conserva la parte inferior de EN.

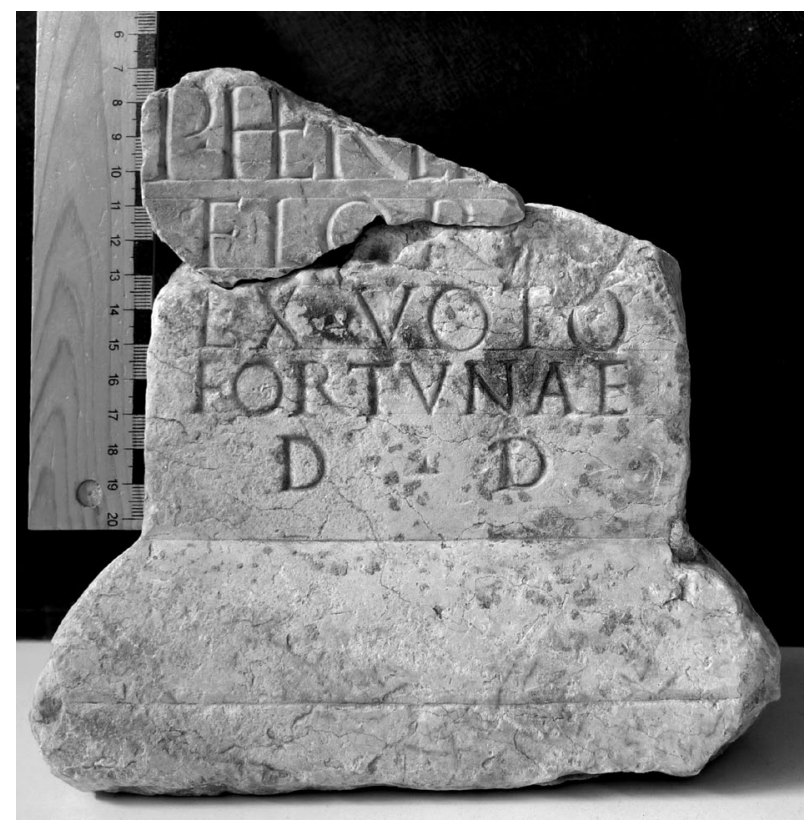

$P($ ublius $) \cdot$ Heren [nius]

Floru[s]

ex voto

Fortunae

$5 d($ ono $) \cdot d($ edit $)$ 
El ara fue dedicada por Publius Herennius Florus a la diosa Fortuna, de la que es bien conocida su relación con los balnearios (González Fernández, 2003). El nomen Herennius es frecuente en Hispania (Abascal, 1994, 149-150), y se ha documentado en diversas ocasiones en Valentia y su territorio con el mismo praenomen (CIL II $2 / 14,31$ y CIL II $2 / 14,120)$. El cognomen Florus también aparece con cierta frecuencia en la provincia Hispania citerior (en Valentia: $\mathrm{CIL} \mathrm{II}^{2} / 14$, 93c; en Saguntum: CIL II $2 / 14,299$ y CIL II $2 / 14,663$ ). En la dedicatoria se emplea la fórmula dono dedit.

Apareció en el ámbito del santuario y termas romanas de la partida de Mura y actualmente se conserva en el Museo Arqueológico de Llíria (MALL).

Por el tipo de letra debe fecharse a finales del s. I o primera mitad del s. II d.C.

\section{OBRA PÚBLICA}

\section{FRISO DE UN EDIFICIO PÚBLICO}

Fragmento de un gran friso de piedra caliza local (pedra de Llíria), perteneciente a un edificio público. Sólo se encuentra alisada la cara frontal. Dimensiones: $30,5 \times(36) \times 16,5$. La altura de las letras es de 23,5 $\mathrm{cm}$. Por encima y debajo de ellas hay un espacio libre de $3 \mathrm{~cm}$. La interpunción es triangular orientada hacia abajo, con una marcada curvatura hacia la izquierda.

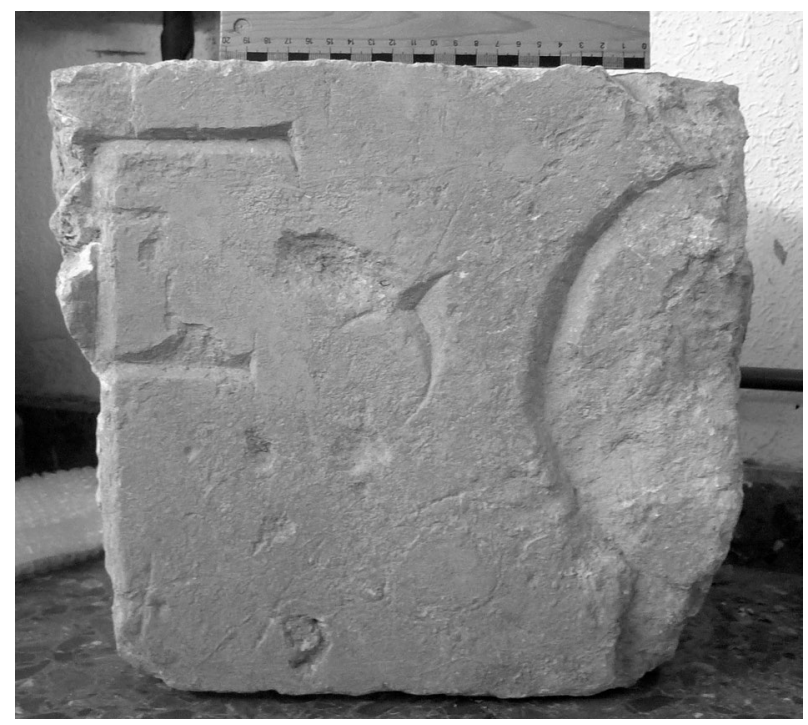

$$
[-] f(i l i-) \cdot G(\text { aleria })[-]
$$

De esta inscripción monumental se conservan únicamente referencias a la filiación del personaje que con bastantes probabilidades dedicaría el edificio del que formaba parte el friso. Las dimensiones de las letras son extraordinarias y en Edeta únicamente disponemos de un paralelo para ellas: otro fragmento de friso, también localizado en el santuario y termas de Mura, atribuido al senador consular edetano M. Cornelius
Nigrinus (Corell y Escrivà, 1998, 136). Teniendo en cuenta las extraordinarias dimensiones de la inscripción, no descartamos un posible emplazamiento en el friso de la basilica thermarum de las termas mayores de Mura, donde se recuperó. Se conserva en el Museo Arqueológico de Llíria.

Por la forma de las letras y el lugar de hallazgo, esta inscripción debe datarse en el último tercio del s. I d.C.

\section{HONORÍFICAS}

\section{Pedestal dedicado a Gratia Maximilla}

Pedestal de piedra caliza local alisada por tres de sus caras, con marco moldurado, con cima reversa en su cara frontal y con listeles en los laterales. En su parte superior presenta un rebaje trapezoidal, en forma de cola de milano ( $27 \times 17 / 11 \times 10$ de profundo), para acoplar el bloque a otra pieza, tal vez a la cornisa. Sus dimensiones son 93,5 x 58 x $53 \mathrm{~cm}$. El campo epigráfico mide $39,5 \times 45 \mathrm{~cm}$. Hasta el inicio del texto hay un espacio libre de $3 \mathrm{~cm}$. La altura de las letras es de $6,5$ (v. $1-4), 6$ (v. 5), 5,8 (v. 6), 4,8 (v.7) y $4,2 \mathrm{~cm}$ (v. 8). Hasta final del campo epigráfico el espacio libre es de $12,5 \mathrm{~cm}$. Interpunción triangular orientada hacia abajo.

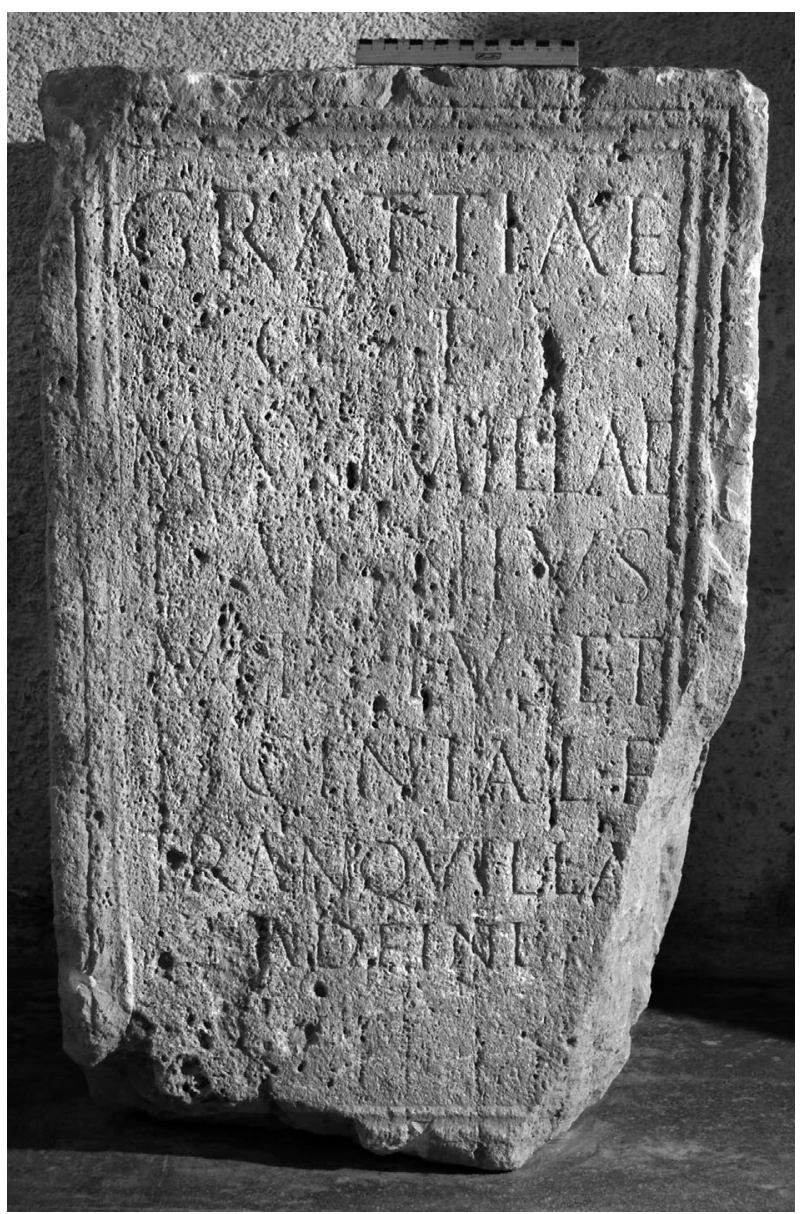




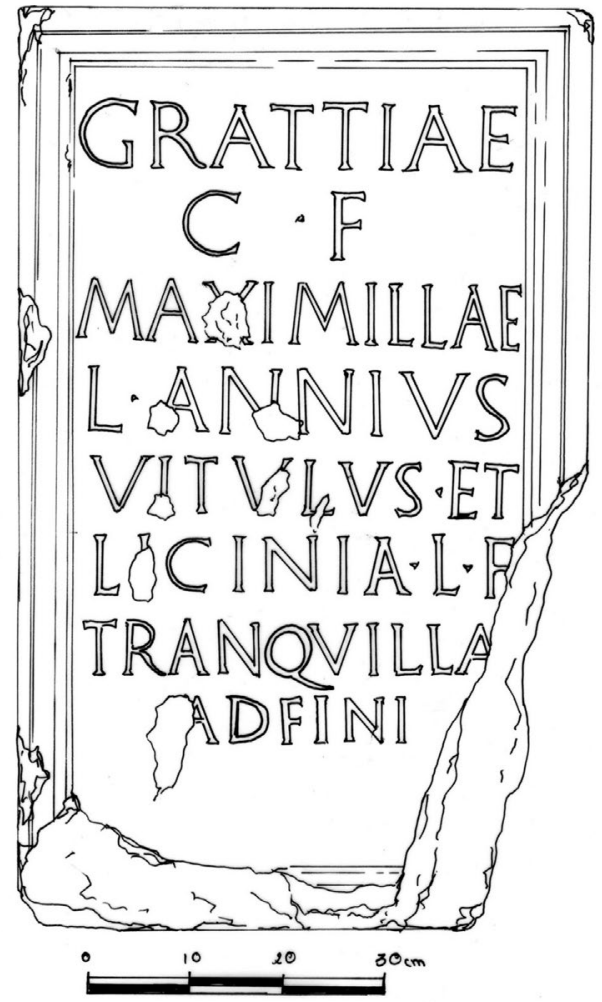

Grattiae

$C($ ai $) \cdot f($ ilia $)$

Maximillae

L(ucius) $\cdot$ Annius

5 Vitulus $\cdot$ et

Licinia $\cdot L($ uci $) \cdot f($ ilia $)$

Tranquilla

adfini

Con bastante probabilidad podemos suponer que esta inscripción estaría situada en el foro de la ciudad, donde se dedicó este pedestal en memoria de Grattia Maximilla, importante mujer de Edeta que podemos relacionar con otros personajes de las vecinas ciudades de Valentia (CIL II $/ 14,83$ ) y del territorium de Saguntum (en Onda, CIL II $2 / 14,739$ ), en cuyos territorios se concentra la mayor parte de las inscripciones de la gens Grattia (Abascal, 1994, 147). En opinión del profesor Alföldy (1977, 18-19) nuestro personaje también estaría emparentado con Baebia L. f. Fulvia Claudia Paulina Grattia Maximilla, una mujer de rango senatorial que aparece en una inscripción de Roma (CIL VI 1361), y con el flamen provincial M. Valerius Propinquus M.f. Gratius Cerealis (Alföldy, 1973, 81).

Dedican la inscripción dos personajes próximos, tal vez familiares políticos -adfini-, L. Annius Vitulus y Licinia Tranquilla. El nomen Annius con el mismo praenomen se documenta en Saguntum (CIL II2/14, 400). El cognomen Vitulus, frecuente en Hispania (Abascal, 1994, 548) se encuentra también documentado en la vecina ciudad de Saguntum (CIL II ${ }^{2} / 14$, 391). Los Licinii, conocidos en Saguntum (Corell, 2002) están presentes también en Valentia (CIL2/14,
21). El cognomen Tranquilla es menos frecuente en Hispania (Abascal, 1994) y conocemos un caso en la cercana ciudad de Valeria. La fórmula de parentesco adfini es utilizada en Saguntum (CIL II ${ }^{2} / 14,338$ ) y con una ligera variante en Valentia (CIL II $2 / 14,72 \mathrm{a})$.

Este monumento se recuperó durante las obras de urbanización de la U.E. 14, algo alejada del núcleo urbano de la ciudad romana y cerca de la bifurcación de las antiguas vías que conducían a Saguntum y a Valentia. Se conserva en el Museo Arqueológico de Llíria.

Por el tipo de monumento y la forma de las letras, el pedestal con inscripción debe datarse a finales del s. I. d.C.

\section{FUNERARIAS}

\section{Estela de CoRnelius Festus}

Estela de piedra azul de Alcublas (Valencia), reutilizada como umbral en una estancia del hospitium del santuario y termas romanas de Edeta.

Sus dimensiones son 135 x 48,5/52 x 30/31 cm. En la parte superior hasta el inicio de la inscripción hay un espacio libre de $21 \mathrm{~cm}$. La altura de las letras es de 5,8 (v. 1.) y de $3,8 \mathrm{~cm}$ (v. 2). Desde el final del texto hasta el final de la estela hay $105 \mathrm{~cm}$.

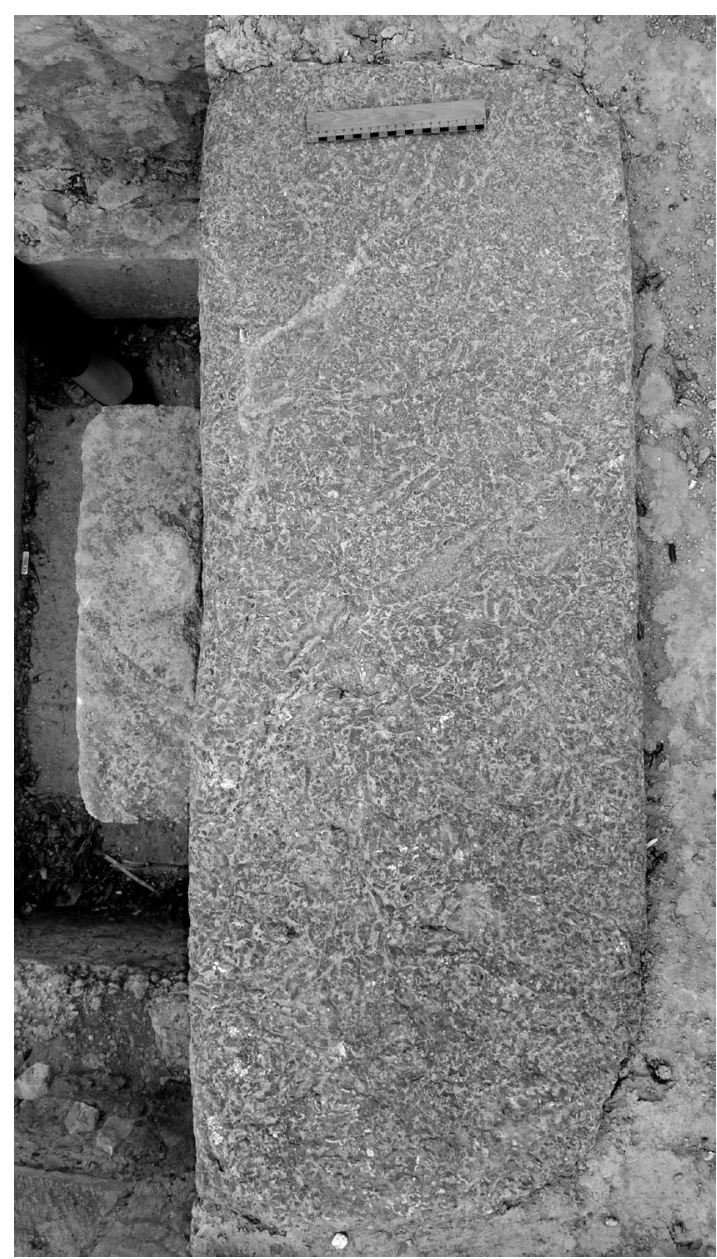



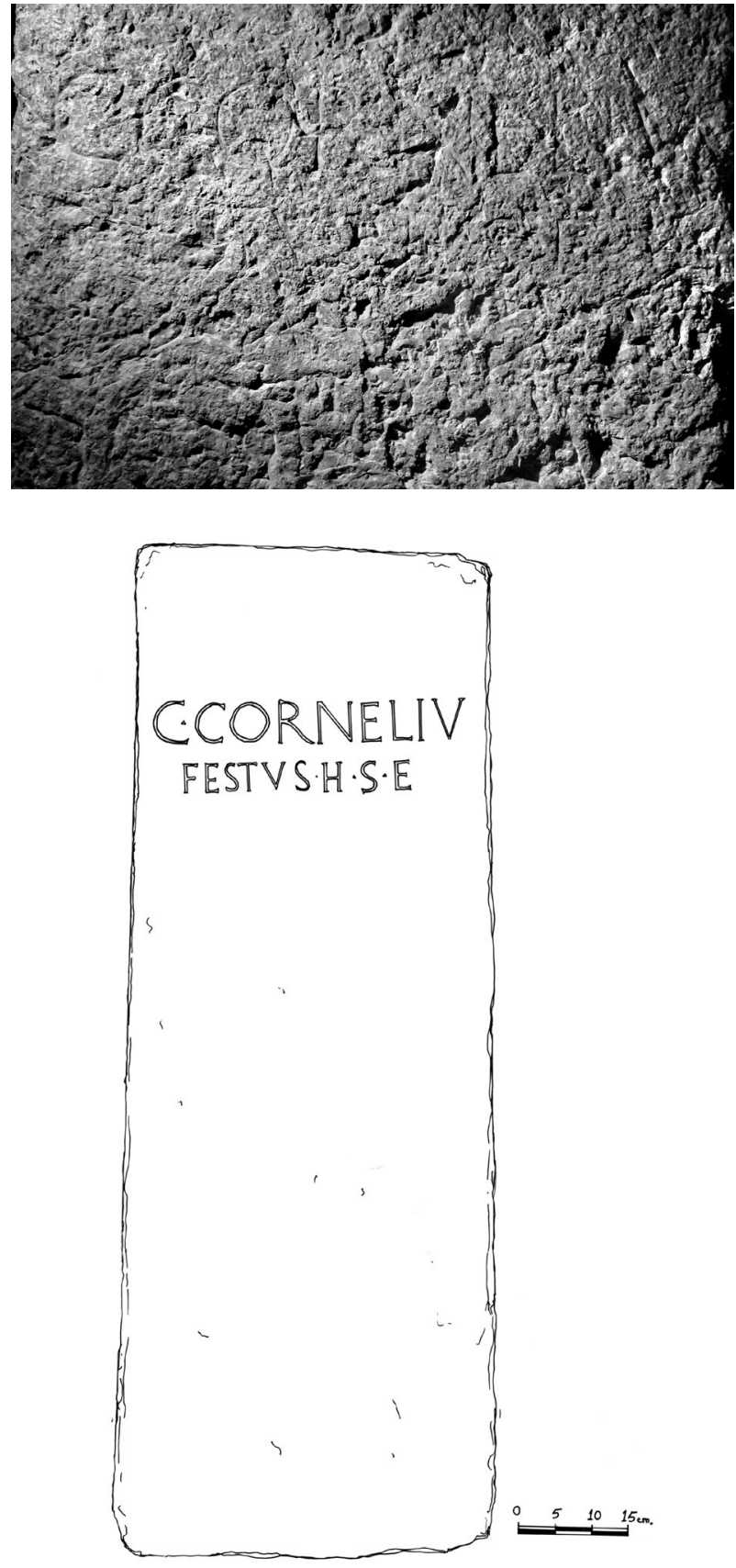

$C \cdot$ Corneliu $[s]$

Festus $\cdot h($ ic $) \cdot s($ itus $) \cdot e(s t)$

La inscripción, bastante desgastada por la posición en la que fue reubicada, presenta un formulario muy simple y en ella únicamente figura el nombre del difunto C. Cornelius Fuscus, en nominativo, acompañado de la fórmula funeraria $h($ ic) $s($ itus $) e(s t)$ indicando el lugar de la sepultura.

El gentilicio Cornelius, muy frecuente en Hispania (Abascal, 1994, 116-125), está bien documentado en Edeta (Corell, 2008), mientras que el masculino Festus, con cierta presencia en la Península Ibérica (Abascal, 1994, 362) era ya conocido en Saetabis (CIL II 3632) y en los territoria de Saguntum y Dianium (CIL $\mathrm{II}^{2} / 14,629$ y II 3610$)$.
La inscripción se conserva in situ en la zona arqueológica del santuario y termas romanas de Mura (Llíria), en un umbral del denominado hospitium, donde fue reutilizada a finales del s. I d.C.

La estela, reutilizada en una construcción de época flavia como se ha comentado, debe datarse en época augustea o primera mitad del siglo I.

\section{Estela de GRATtia MAURUCA}

Estela de cabecera semicircular de piedra azul de Alcublas (Valencia). En la parte inferior ha sufrido algunos desperfectos pero se conserva completa. Mide 93 $\mathrm{cm}$ de altura, 42/38 de anchura y 19 de grosor. Hasta el inicio del texto tiene un espacio libre de $14,5 \mathrm{~cm}$ que alcanza los $49 \mathrm{~cm}$ por la parte inferior. La altura de las letras es de 5,5 (v. 1), 4,8/5 (v. 2), 4,8 (v. 3), 4,5 (v. 4) y $4,2 \mathrm{~cm}$ (v. 5 ).
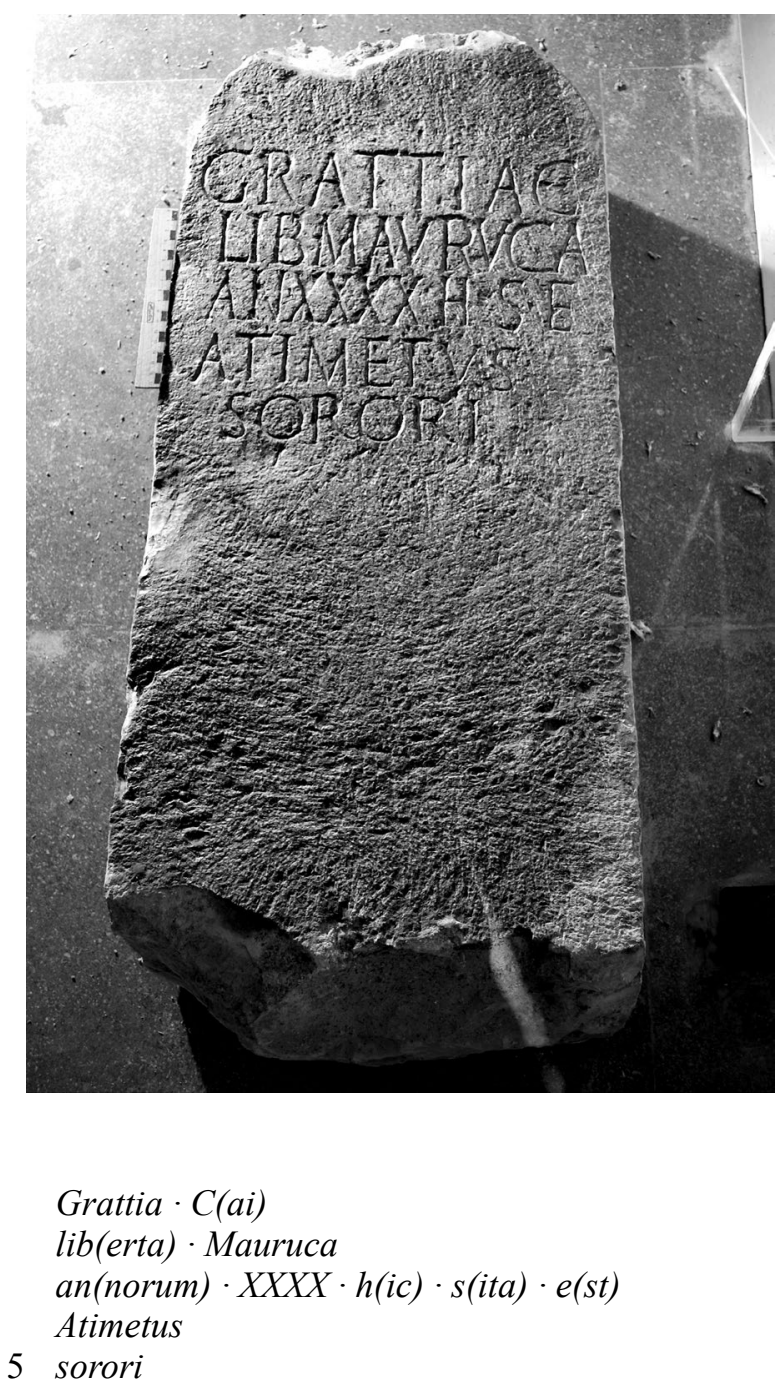

Inscripción funeraria dedicada a Grattia Mauruca por su hermano Atimetus. Grattia sería una liberta privada, probablemente relacionada con Grattia Maximilla, hija de Caius, de la inscripción n. ${ }^{\circ} 3$. El cognomen 
Mauruca parece corresponder a su origo y la terminación «uca» debe relacionarse con su filiación. A continuación se indican los años y la fórmula funeraria $h$ (ic) $s$ (ita) e(st).

Dedica la inscripción su hermano Atimetus. Este es un nombre personal de esclavo, probablemente manumitido, poco frecuente en Hispania (Abascal, 1994, 289). Conocemos con este cognomen un liberto de $\mathrm{Va}$ lentia (CIL II $\left.{ }^{2} / 14,65\right)$.

La inscripción se recuperó en las excavaciones de la partida de Mura, cerca de la necrópolis denominada «de la Puerta Este» y se conserva en el Museo Arqueológico de Llíria.

Por el tipo de letra y el formulario puede datarse en el siglo I d. C.

\section{Placa fUneraria}

Placa de mármol blanco con las caras anterior y posterior pulidas. Sus dimensiones son $(27,5) \times(16,5) \times 2$. E1 lateral derecho está alisado y corresponde a uno de los extremos de la placa. El fragmento superior fue publicado por Corell y Escrivà $\left(1998,139\right.$ y 144, n. $.^{\circ} 9=\operatorname{HEp} 8$, $1998,498)$, así como por Corell $\left(2008,137-138\right.$, n. $\left.^{\circ} 91\right)$.

Conserva parte de dos líneas e indicios de una tercera en su parte superior. La altura de las letras en las líneas conservadas es de 8,5 (v. 1) y $8,2 \mathrm{~cm}$ (v. 2). Hasta el final se conserva un espacio libre de $5 \mathrm{~cm}$, lo que podría marcar el final de la inscripción.

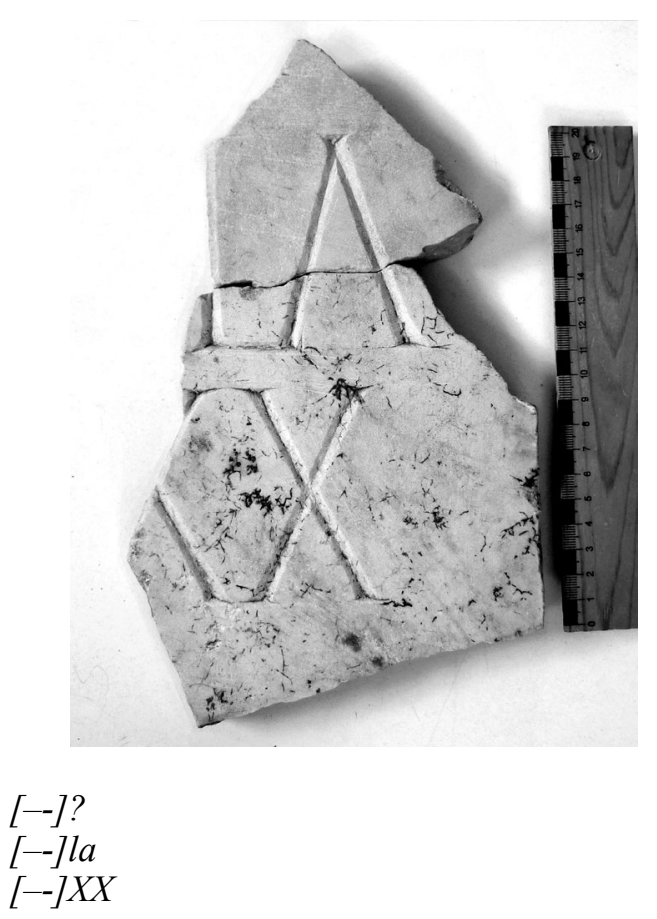

Conserva el final de un cognomen femenino y numerales relativos a la edad de su muerte, probablemente acaecida a los 20 o 30 años.

Ambos fragmentos aparecieron en el santuario y termas romanas de Mura, donde debieron ser reutilizados, y se conservan en el Museo Arqueológico de Llíria.

La placa con la inscripción podría datarse de finales del s. I, principios del s. II d.C.

\section{INSTRUMENTUM DOMESTICUM}

\section{DOLIUM}

Dolium defossus del que se conserva, prácticamente completo, el tercio superior. El borde es ligeramente pendiente y presenta una moldura en su extremo. Conserva diversas perforaciones por debajo del borde y algunas grapas de plomo. En la parte inferior conserva una ranura que señalaba el inicio de la parte enterrada del dolium, de la que no se conservan restos. Sus dimensiones son $61 \mathrm{~cm}$ diámetro del borde y 110 cm de diámetro máximo; la altura conservada es de $45 \mathrm{~cm}$.

En su pared exterior, sobre el hombro, in campana, presenta tres grafitos en cursiva y unas líneas incisas, tal vez una marca de contabilidad, realizados post cocturam utilizando diferentes instrumentos. La disposición de los grafitos sigue la dirección contraria a la de las agujas del reloj; uno de ellos fue inscrito en posición vertical, de panza a borde, y el resto siguiendo la habitual trayectoria horizontal.

Los grafitos son los siguientes:

\section{Caesi \\ B(onorum) $\cdot p$ (ossesor) \\ IIII \\ M(odii) $X X s$ (extarii) $V I$}

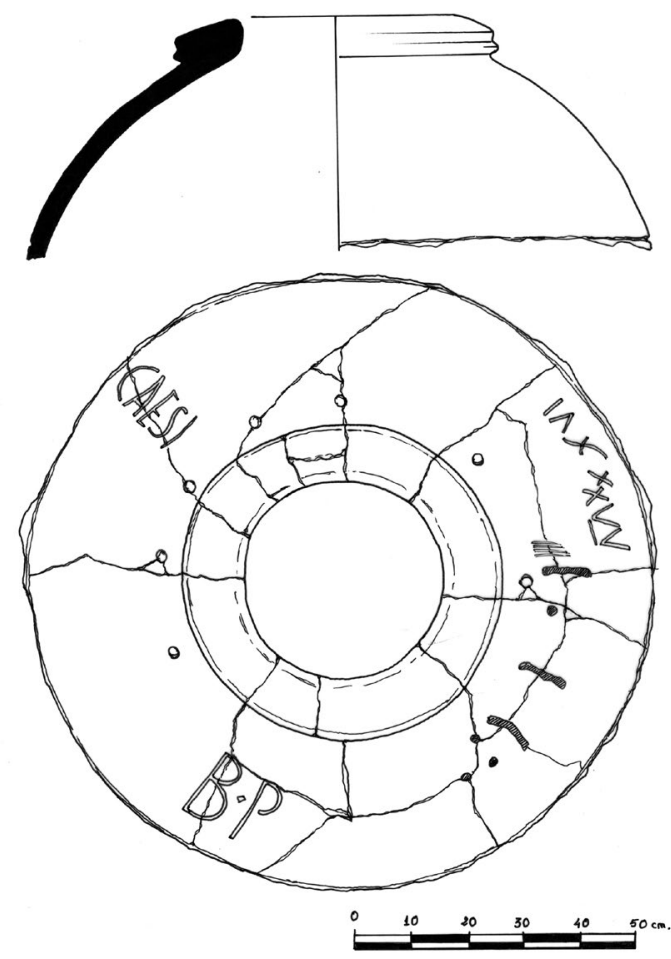




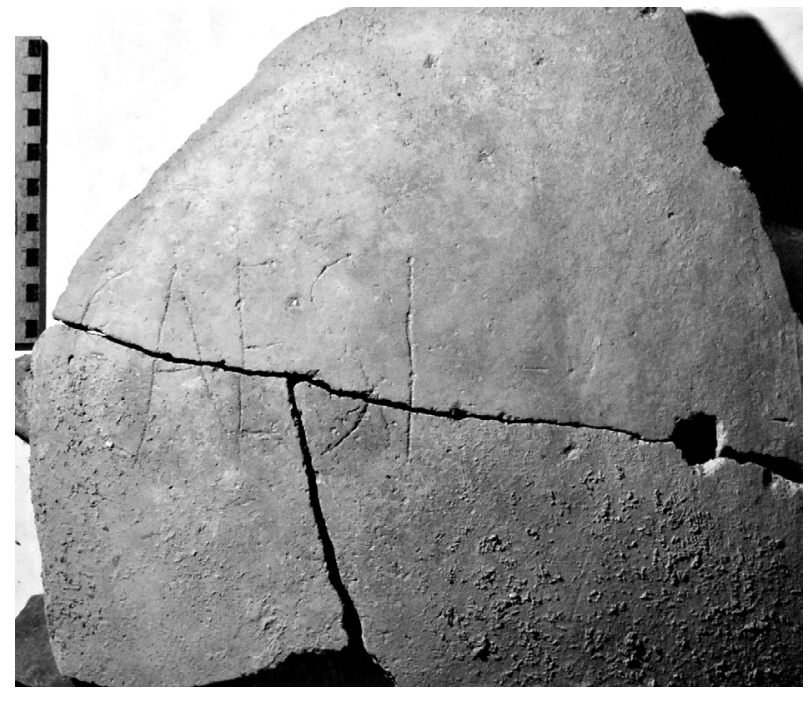

7a. Caesi. Genitivo singular del nomen latino Caesius. Escritura cursiva. Medidas: 18,8 x $10,5 \mathrm{~cm}$. Trazo inciso con un instrumento fino; su grosor es de unos 2/3 mm. Las letras tienen entre 9,5 y $10,3 \mathrm{~cm}$ de altura. Caesius es un nomen documentado en Hispania (Abascal, 1994, 103). Este gentilicio podría designar al propietario del dolium o, quizás, al propietario de la tierra de la que se obtiene el producto envasado.

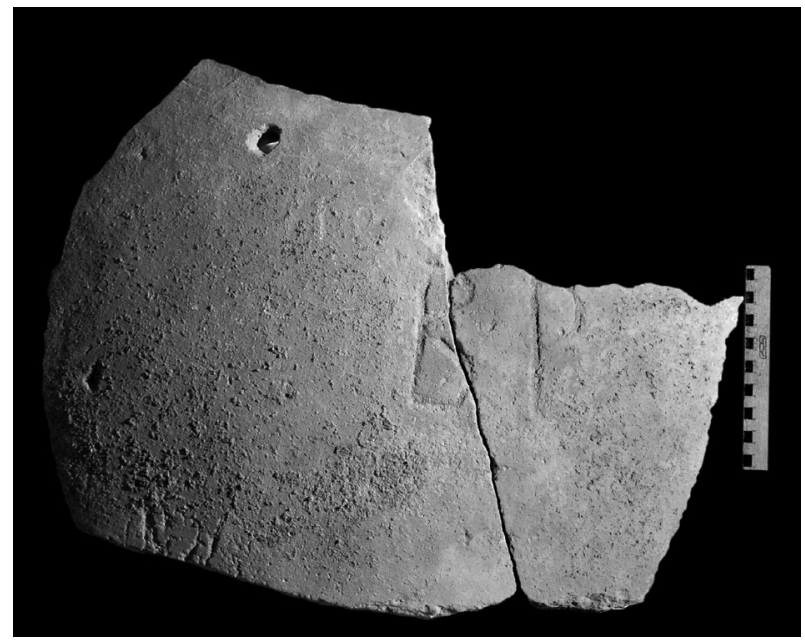

7b. B(onorum) p(ossessor). Escritura cursiva. Medidas: 13 x $12 \mathrm{~cm}$. Trazo inciso con un instrumento de punta ancha; su grosor es de unos $8 \mathrm{~mm}$. Las letras tienen entre 12 y $12,5 \mathrm{~cm}$ de altura. La abreviación BP se interpreta como la fórmula bonorum possessio (Álvarez de la Braña, 1884, 27) en referencia a la fórmula hereditaria (Ortega Carrillo de Albornoz, 1999, 314-316) a través de la cual fue adquirida la propiedad de la tierra donde se producía el producto envasado en el dolium, o bien como bonorum possessor si se refiere a Caesi como el propietario de estas tierras (AAVV, 1963, 587-595).

7c. IIII parece corresponder a alguna anotación contable.

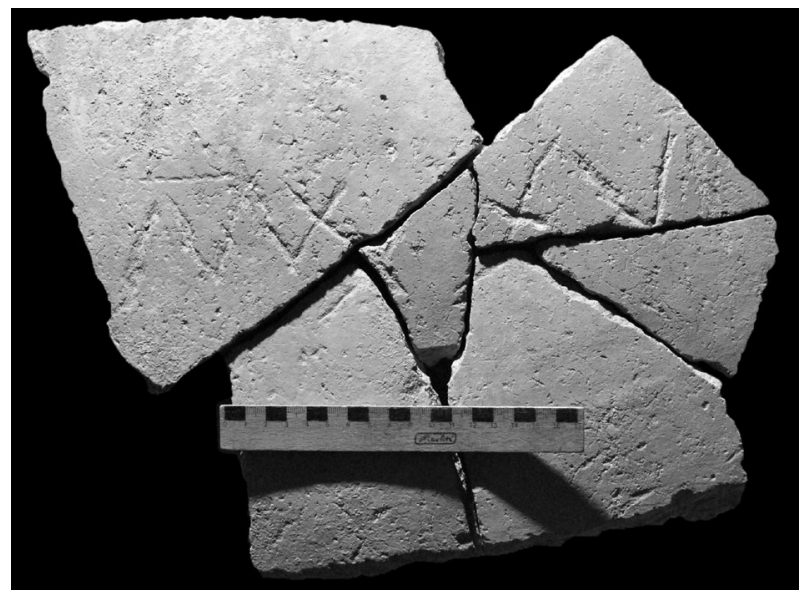

7d. M(odii) XXs(extarii) VI. Numeral relativo a la capacidad. Medidas: 30,5 x 5/6cm. Trazo inciso con un instrumento de punta ancha; su grosor es de unos $4 / 5 \mathrm{~mm}$. Las letras tienen entre 5,5 y $6 \mathrm{~cm}$ de altura. La inscripción arranca con una $M$ con una línea horizontal que la cubre, y para la que no encontramos otra opción que su lectura como $M$ (odii), seguida del numeral XX, y a continuación una $S$ barrada, abreviación latina de sextarius, seguida del numeral VI. Se trata, sin duda, de una medida de capacidad de sólidos, lo que nos indica que se trataría de un dolium frumentarium destinado al almacenaje de cereal.

Se recuperó en la Calle de las Ventas, formando parte del relleno interior de un pozo de época romana excavado en el terreno natural. Actualmente se conserva en el Museo Arqueológico de Llíria (MALL).

\section{DoLIUM}

Diversos fragmentos del tercio superior de un dolium, probablemente defossus. El borde es ligeramente pendiente y redondeado en su extremo. Conserva diversas perforaciones por debajo del borde. El diámetro del borde es de $70 \mathrm{~cm}$ y el diámetro máximo alcanza los $115 \mathrm{~cm}$; la altura conservada es de $45 \mathrm{~cm}$.

En su pared exterior, sobre el hombro, in campana, presenta tres grafitos en cursiva, realizados post cocturam utilizando diferentes instrumentos. La disposición de los grafitos sigue la dirección contraria a la de las agujas del reloj, y todos ellos se encuentran dispuestos en sentido horizontal. 

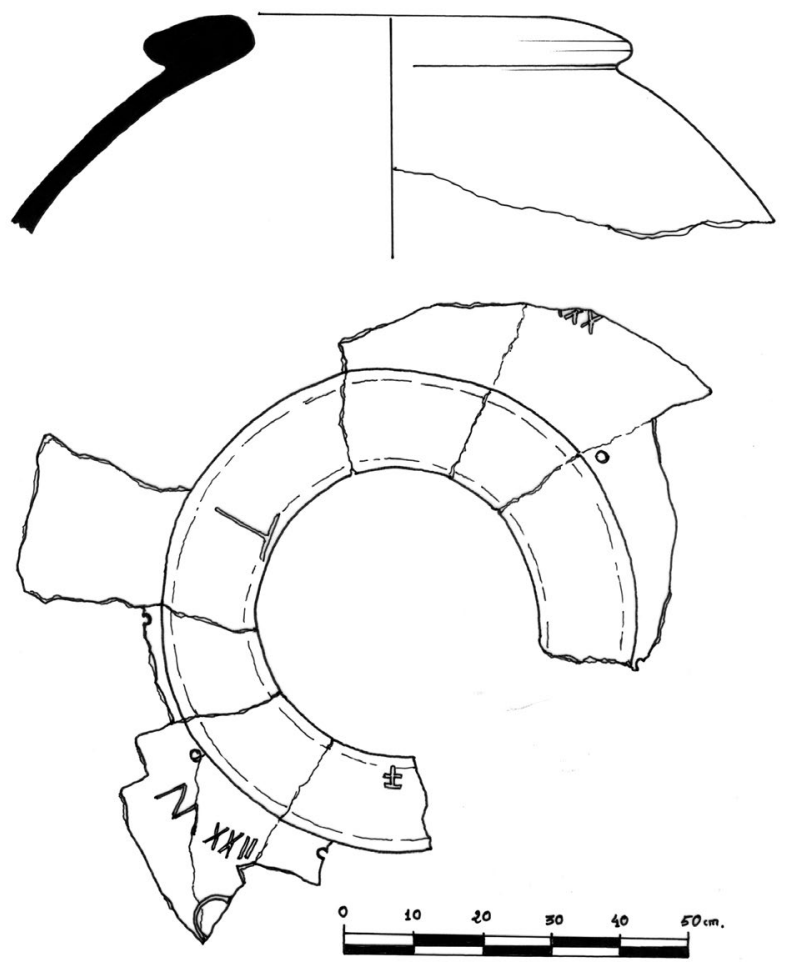

Los grafitos son los siguientes:

$$
\begin{aligned}
& M(\text { odii) XXII } \\
& C[--] \\
& X X[--]
\end{aligned}
$$

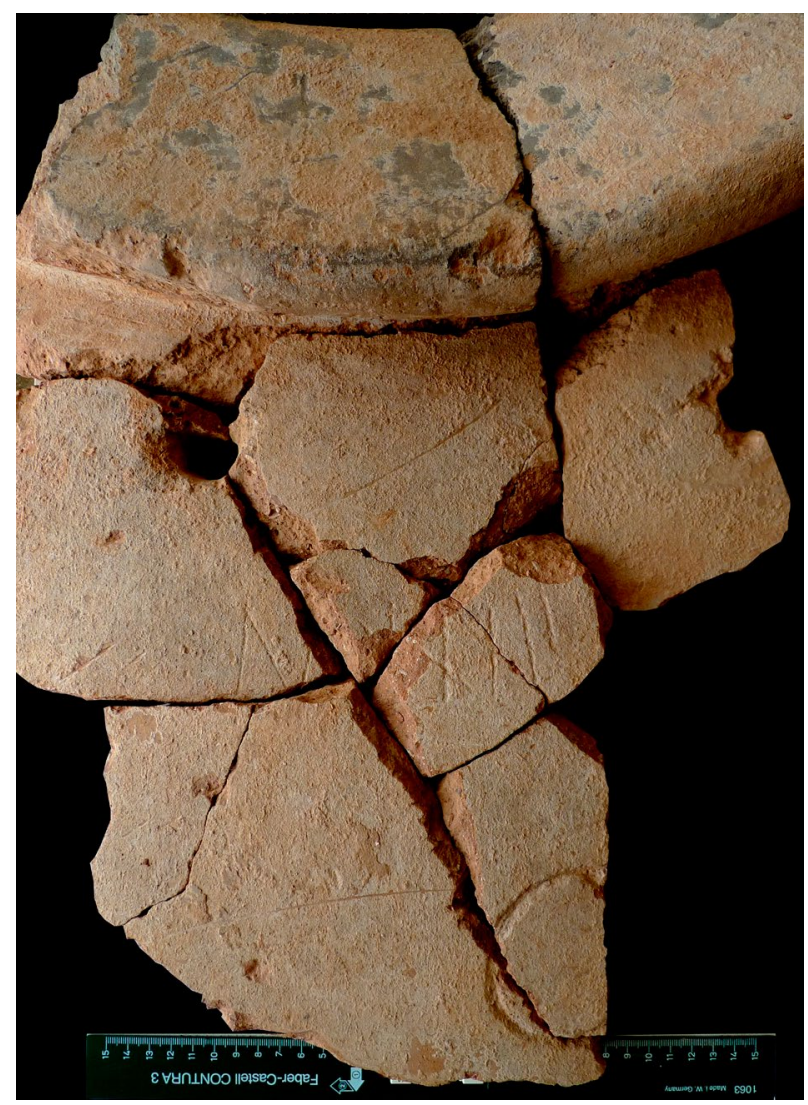

8a M(odii) XXXII. Numeral. Medidas: 13 x 4/3,5 cm. Trazo inciso con un instrumento de punta ancha; su grosor es de unos $2 \mathrm{~mm}$. Letras: entre 4 y $3,5 \mathrm{~cm}$.

La inscripción comienza con la abreviación $M$ de modio, medida de capacidad para sólidos, acompañada del numeral XXXII; la primera cifra se lee con dificultad debido a la rotura de la pieza. A continuación queda un espacio libre y parece improbable la referencia a la capacidad en sextarii.

8b. C[--]. Inicio de un probable nomen o cognomen personal. Trazo inciso con un instrumento de punta ancha, de $5 \mathrm{~cm}$ de grosor. Solo conserva una letra de $8 \mathrm{~cm}$.

Por su proximidad con el dolium anterior podríamos suponer la presencia del genitivo Caesi, aunque no hay suficientes elementos para su atribución.

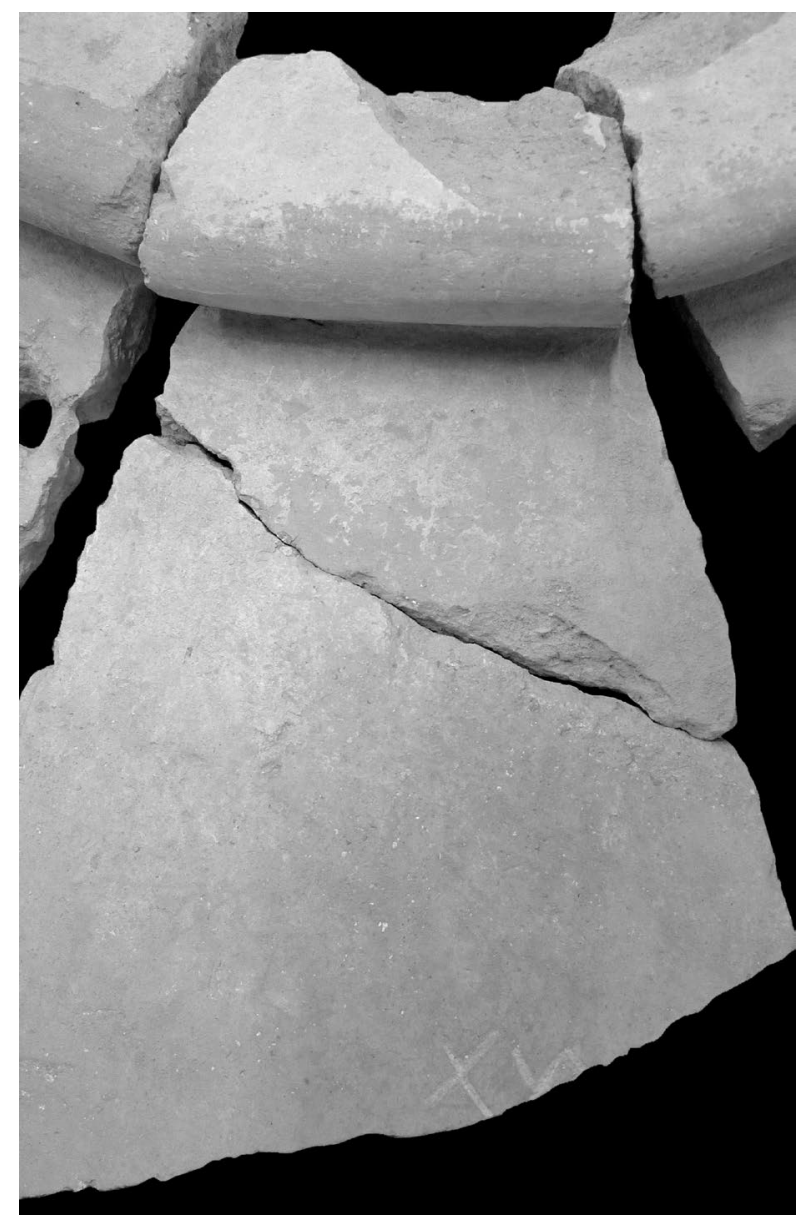

8c. $X X X[--]$. Numeral. Trazo inciso con un instrumento de punta ancha. Dimensiones conservadas: 5 $\mathrm{cm}$; su grosor es de unos $3 \mathrm{~mm}$. La altura de las letras es de $3 \mathrm{~cm}$. Probablemente esta cantidad tenga relación también con la capacidad de la pieza, aunque en esta ocasión, probablemente, estuviera medida en ánforas.

No todos los investigadores consideran que los numerales inscritos en los dolia hagan referencia a la capacidad de los contenedores. En el estudio del 
dolium de Broni, los editores opinan que el signo numérico XXII inscrito sobre el hombro del recipiente plantea problemas de atribución; siguiendo el estudio de Pasqui (Pasqui, 1897) son de la opinión de que el numeral no tiene correspondencia con la capacidad del recipiente, argumentando que ésta es mucho mayor a la capacidad en modii indicada por el numeral (Invernizzi et alii, 1999); no obstante, en la mayoría de los casos, como refleja el estudio de Brenni (1985, 299), los grafitos mencionan la capacidad en modii cuando van precedidos de la abreviación $M$ (Brenni, 1985, 197), y en ánforas cuando van precedidos por las abreviaciones $A$ ó $A M P$, pero también cuando carecen de ella y sólo se inscribe el numeral $(26,26$ 1.) (Brenni, 1985, 193-195).

En el dolium de Edeta aparece una dualidad de registros numerales, que ya se habían documentados con anterioridad en la provincia Hispania citerior sobre el dolium de la villa romana de Santa María de Sales (Viladecans, Barcelona) (Solias, 1985, 116-117, fig. 2, 4) y con mayor claridad en el dolium procedente del Aventino, en Roma (CIL XV, 1, 2523). En nuestra opinión, estos grafitos hacen referencia a un sistema dual de capacidades, uno para sólidos y otro para líquidos, lo que nos permite plantear la posibilidad de que este gran contenedor sirviera como dolium frumentarium $\mathrm{y}$, también, como dolium vinarium.

Se recuperó en la Calle de las Ventas, en el año 2007, formando parte del relleno interior de un pozo de época romana excavado en en terreno natural (U.E. 2003). Actualmente se conserva en el Museo Arqueológico de Llíria (MALL).

Vicente Escrivà Torres
Director
Museo Arqueológico de Llíria
Plaza del Trinquet Vell s/n.
46160 Llíria.
escrivarq@gmail.com
Carmen Martínez Camps
Arqueóloga
carmenmcamps@gmail.com
Ana Sabater Pérez
Arqueóloga
ana.sabater.perez@gmail.com
Xavier Vidal
Arqueólogo municipal
Ayuntamiento de Llíria
Plaça Mayor 1
46160 Llíria
vidal.xavi@gmail.com

\section{BIBLIOGRAFÍA}

AAVV, 1963: Vocabularium Iurisprudentiae Romanae, Vol. I, fasc. III. Amitto-ceterum, Berlín.

ABASCAL, J. M., 1994: Los nombres personales en las inscripciones latinas de Hispania, Murcia.

ALFÖLDY, G., 1973: Flamines Provinciae Hispaniae Citerioris, Anejos de AEspA, 6, Madrid.

ALFÖLDY, G., 1977: Los Baebii de Saguntum, Trabajos Varios del SIP, 56,Valencia.

ALFÖLDY, G y HALFMANN, H., 1973: El edetano M. Cornelius Nigrinus Curiatius Maternus. General de Domiciano y rival de Trajano, Trabajos varios del SIP, 44, Valencia.

ÁLVAREZ DE LA BRAÑA, R., 1884: Siglas y abreviaturas latinas con su significado, por orden alfabético seguidas del calendario Romano y de un catálogo de las abreviaturas que se usan en los documentos pontificios, León.

BRENNI, G. M.A., 1985: The Dolia and the Sea-Borne Commerce of Imperial Rome, Tesis Doctoral. Texas A\&M University.

CIL II²/14-1: G. ALFÖLDY ET ALII, 1995: Corpus Inscriptionum Latinarum, Vol. II: Inscriptiones Hispaniae latinae, Fasc. 14.1, Conventus Tarraconensis. Pars meridionalis conventus Tarraconensis, Berlin.

CORELL, J. 2008: Inscripcions romanes del País Valencià. IV. Edeta i el seu territori, Valencia.

CORELL, J. y ESCRIVÀ, V. 1998: «Novetats epigràfiques d'Edeta i el seu territori. Additamenta ad IrET», Studia Philologica Valentina, 3, 135- 145.

CORELL, J., GÓMEZ, X., ESCRIVÀ, V. y VIDAL, X., 2012: «Grafitos sobre cerámica romana de Edeta (Llíria, València)», en Inscriptions mineures: nouveautés et refléxions, Actes du premier colloque Ductus (Université de Lausanne, 2008), 95-124, Lausanne.

ESCRIVÀ, V., MARTÍNEZ, C. y VIDAL, X., 2001: «Edeta kai Leiria: La ciutat romana d'Edeta de l'època romana a l'antiguitat tardana», Lauro. Quaderns d'historia i societat, 9, 13-91.

GONZÁLEZ FERNÁNDEZ, R., 2003: «La diosa Fortuna. Relaciones con las aguas y los militares. El caso particular del Balneario de Fortuna (Murcia)», Antigüedad y cristianismo: Monografías históricas sobre la Antigüedad tardía 20, 373-386.

INVERNIZZI, R., VECHI, L., ANGELINO, I. y NUZZO, E., 1999: «Scavo di un dolium a Broni (Pavia)», Archeología, Uomo, territorio, 18, 53-61.

ORTEGA CARRILlO DE ALBORNOZ, A., 1999: Derecho Privado Romano, Málaga.

PASQUI, A., 1897: «La villa pompeiana della Pisanella presso Boscoreale», Monumenti Antichi dell'Accademia dei Lincei, VII, 397-554.

SOLÍAS Y ARIS, J. M. ', 1985: «Introducció a l'estudi de les activitats econòmiques d'una vil·la laietana», Pyrenae, 21, 113-122. 